\title{
SINTESIS GEOPOLIMER DARI METAKAOLIN DAN ABU BAMBU UNTUK APLIKASI SEMEN: KAJIAN WAKTU IKAT DAN MIKROSTRUKTUR
}

\author{
Aprilina Purbasari $^{{ }^{*}}$ dan Tkokorde Walmiki Samadhi ${ }^{2}$ \\ ${ }^{1}$ Departemen Teknik Kimia, Fakultas Teknik, Universitas Diponegoro \\ Jl. Prof. Soedarto, Kampus Tembalang, Semarang 50275 \\ ${ }^{2}$ Departemen Teknik Kimia, Fakultas Teknologi Industri, Institut Teknologi Bandung \\ Jl. Ganesha No. 10, Bandung 40132 \\ *Email: aprilina.purbasari@che.undip.ac.id
}

\begin{abstract}
Abstrak
Geopolimer merupakan polimer anorganik dengan ikatan polimerik Si-O-Al yang dapat dimanfaatkan sebagai pengganti semen Portland karena proses produksinya berlangsung pada suhu rendah dibandingkan produksi semen Portland dengan bahan baku material alumino-silikat yang dapat berasal dari mineral alam dan limbah padat. Pada penelitian ini geopolimer dibuat dari campuran metakaolin dan abu bambu dengan aktivator alkali campuran larutan $\mathrm{KOH} 10 \mathrm{~N}$ dan larutan $\mathrm{Na}$-Silikat serta campuran larutan $\mathrm{NaOH} 10 \mathrm{~N}$ dan larutan Na-Silikat. Waktu ikat pembentukan geopolimer dan mikrostruktur geopolimer yang dihasilkan telah dikaji pada penelitian ini. Waktu ikat awal dan akhir pembetukan geopolimer dengan aktivator alkali campuran larutan $\mathrm{KOH} 10 \mathrm{~N}$ dan larutan Na-Silikat lebih pendek dibandingkan dengan aktivator alkali campuran larutan $\mathrm{NaOH} 10 \mathrm{~N}$ dan larutan Na-Silikat. Hasil analisis SEM menunjukkan bahwa pada kedua geopolimer terbentuk fase kontinyu. Untuk hasil analisis XRD, pada geopolimer dengan aktivator alkali campuran larutan KOH 10 $N$ dan larutan Na-Silikat terdapat leucite dan quartz, sedangkan pada geopolimer dengan aktivator alkali campuran larutan $\mathrm{NaOH} 10 \mathrm{~N}$ dan larutan Na-Silikat terdapat hydrosodalite dan quartz. Pada kedua geopolimer menunjukkan adanya struktur amorf.
\end{abstract}

Kata kunci: abu bambu, geopolimer, metakaolin, mikrostruktur, semen, waktu ikat

\section{PENDAHULUAN}

Semen Portland merupakan material bangunan yang telah banyak digunakan secara luas dan penggunaannya cenderung mengalami peningkatan. Menurut Departemen Perindustrian (2009) konsumsi semen di Indonesia pada tahun 2009 sebesar 40 juta ton dan diasumsikan meningkat sebesar $5 \% /$ tahun. Pada kenyataannya konsumsi semen di Indonesia pada tahun 2015 lebih besar dari yang diasumsikan, yaitu sebesar 60,6 juta ton (Semen Indonesia, 2015).

Proses produksi semen yang melibatkan peleburan bahan baku mineral hingga suhu sekitar $1400{ }^{\circ} \mathrm{C}$ membutuhkan energi besar, yaitu sekitar $3 \mathrm{GJ} /$ ton klinker untuk proses kering yang paling efisien, sementara untuk proses basah kebutuhan energinya dapat mencapai lebih dari dua kalinya (Gartner, 2004). Emisi gas $\mathrm{CO}_{2}$ yang dihasilkan pada produksi semen sekitar 0,9 ton $\mathrm{CO}_{2}$ /ton semen dan telah berkontribusi sekitar 5-7\% dari emisi gas $\mathrm{CO}_{2}$ global (Benhelal dkk., 2013).

Geopolimer dapat digunakan sebagai alternatif pengganti semen Portland. Proses produksi geopolimer berlangsung pada suhu rendah (di bawah $100{ }^{\circ} \mathrm{C}$ ) dengan mereaksikan bahan yang mengandung oksida alumino-silikat dan aktivator alkali untuk menghasilkan ikatan polimerik Si-O-Al dengan struktur amorf hingga semikristalin (Davidovits, 2017). Penelitian-penelitian mengenai aplikasi geopolimer sebagai pengganti semen Portland menunjukkan kekuatan mekanik yang tinggi, ketahanan terhadap suhu tinggi/rendah dan kondisi asam/basa, serta pengurangan emisi $\mathrm{CO}_{2}$ hingga $90 \%$. Selain itu produksi geopolimer dari limbah padat berpotensi mengurangi beban lingkungan dengan biaya produksi yang $10-30 \%$ lebih rendah daripada biaya produksi semen Portland (Komnitsas dan Zaharaki, 2007).

Bahan baku geopolimer adalah material alumino-silikat, baik berupa mineral alam maupun limbah padat. Mineral alam yang telah banyak dipelajari untuk pembuatan geopolimer adalah kaolin $\left(\mathrm{Al}_{2} \mathrm{O}_{3} \cdot 2 \mathrm{SiO}_{2} \cdot 2 \mathrm{H}_{2} \mathrm{O}\right)$ dan metakaolin $\left(\mathrm{Si}_{2} \mathrm{O}_{5}, \mathrm{Al}_{2} \mathrm{O}_{2}\right)$ yang merupakan hasil kalsinasi kaolin pada suhu di atas $550{ }^{\circ} \mathrm{C}$ (Davidovits, 2008). Limbah padat yang dapat dimanfaatkan sebagai bahan baku geopolimer adalah abu terbang, terak, dan abu biomasa. Abu biomasa yang telah dimanfaatkan untuk pembuatan geopolimer antara lain adalah abu sekam padi (Tippayasam dkk., 2014) dan abu 
kelapa sawit (Hawa dkk., 2013). Abu bambu juga berpotensi dimanfaatkan sebagai bahan baku geopolimer karena mengandung silika pada kadar yang tinggi (Purbasari dkk., 2016).

Pada penelitian ini geopolimer dibuat dengan bahan baku campuran metakaolin dan abu bambu dengan aktivator alkali campuran larutan $\mathrm{KOH} 10 \mathrm{~N} / \mathrm{NaOH} 10 \mathrm{~N}$ dan larutan NaSilikat. Waktu ikat pembentukan geopolimer dan mikrostruktur geopolimer yang dihasilkan akan dikaji pada penelitian ini. Analisis mikrostruktur geopolimer meliputi Scanning Electron Microscope (SEM) dan X-Ray Diffraction (XRD).

\section{METODOLOGI}

Metakaolin yang digunakan pada penelitian ini diperoleh dengan mengkalsinasi kaolin pada suhu $550{ }^{\circ} \mathrm{C}$ selama 3 jam. Kaolin berasal dari Kepulauan Bangka Belitung dengan komposisi utama $\mathrm{SiO}_{2}(53,90 \%)$ dan $\mathrm{Al}_{2} \mathrm{O}_{3}$ $(42,43 \%)$. Abu bambu diperoleh dari hasil pembakaran bambu apus (Gigantochloa apus) yang diperoleh di kota Semarang. Abu bambu mempunyai komposisi utama $\mathrm{SiO}_{2}(58,60 \%)$ dan $\mathrm{K}_{2} \mathrm{O} \quad(26,43)$. Baik metakaolin maupun abu bambu diayak terlebih dahulu dengan ayakan standar 100 mesh sebelum digunakan sebagai bahan baku geopolimer.

Material alumino-silikat yang terdiri dari campuran metakaolin dan abu bambu dengan perbandingan massa 1:0,25 dicampur dengan aktivator alkali dalam mixer selama 6 menit sehingga membentuk pasta geopolimer. Perbandingan massa material alumino-silikat terhadap aktivator alkali adalah 1:1,1. Aktivator alkali yang digunakan adalah campuran larutan $\mathrm{KOH}$ $10 \mathrm{~N}$ dan larutan Na-Silikat serta campuran larutan $\mathrm{NaOH} 10 \mathrm{~N}$ dan larutan Na-Silikat. Perbandingan massa larutan $\mathrm{KOH} 10 \mathrm{~N}$ dan larutan $\mathrm{NaOH} 10 \mathrm{~N}$ terhadap larutan NaSilikat masing-masing adalah 1:2.

Uji waktu ikat (setting time) pasta geopolimer menggunakan alat Vicat sesuai dengan ASTM C191 (2008). Pasta dimasukkan dalam cincin dengan tinggi 40 $\mathrm{mm}$ pada alat Vicat. Jarum Vicat berdiameter 1,00 $\pm 0,05 \mathrm{~mm}$ dengan panjang tidak kurang dari $50 \mathrm{~mm}$ yang berada 10 $\mathrm{mm}$ di atas pasta dibiarkan berpenetrasi ke dalam pasta.

Setelah jarum Vicat tidak berubah posisi selama 30 detik, kedalaman penetrasi jarum Vicat dari permukaan pasta diamati. Penetrasi jarum Vicat dilakukan secara periodik dengan selang waktu 15 menit dan berjarak minimal $5 \mathrm{~mm}$ dari penetrasi sebelumnya dan minimal $10 \mathrm{~mm}$ dari tepi cincin hingga jarum Vicat tidak dapat berpenetrasi ke dalam pasta. Waktu ikat awal (initial setting time) adalah waktu yang diperlukan saat jarum Vicat mencapai kedalaman penetrasi $25 \mathrm{~mm}$ dan waktu ikat akhir (final setting time) adalah waktu yang diperlukan saat jarum Vicat tidak dapat berpenetrasi ke dalam pasta.

Untuk pengujian mikrostruktur, pasta geopolimer dicetak dalam cetakan berbentuk kubus ukuran $5 \times 5 \times 5 \mathrm{~cm}$ selama 24 jam. Pasta geopolimer kemudian dilepas dari cetakan dan dilakukan pematangan (curing) pada suhu $60{ }^{\circ} \mathrm{C}$ di oven selama 8 jam dan didiamkan pada suhu kamar selama 28 hari. Analisis SEM geopolimer dilakukan dengan alat Hitachi SU3500 pada accelerating voltage $5 \mathrm{kV}$, working distance $20 \mathrm{~mm}$, dan perbesaran 5000x. Sampel yang akan diuji dilapisi dengan emas terlebih dahulu. Adapun analisis XRD geopolimer dilakukan dengan alat Bruker D8 Advance pada suhu kamar dengan kondisi $40 \mathrm{kV}, 35 \mathrm{~mA}$, radiasi $\mathrm{CuK} \alpha$, dan sudut scanning $2 \theta: 5-80^{\circ}$.

\section{HASIL DAN PEMBAHASAN}

\subsection{Waktu ikat}

Waktu ikat awal (initial setting time) dan waktu ikat akhir (final setting time) geopolimer berguna dalam aplikasinya sebagai semen, yaitu memberikan informasi waktu yang tersedia untuk transportasi, penempatan, dan pemadatan geopolimer (Hardjito dkk., 2008). Waktu ikat awal dan waktu ikat akhir geopolimer dari metakaolin dan abu bambu dengan aktivator alkali campuran larutan $\mathrm{KOH} 10 \mathrm{~N}$ dan larutan Na-Silikat masing-masing adalah 426,2 menit dan 540 menit, sedangkan dengan aktivator alkali campuran larutan $\mathrm{NaOH} 10 \mathrm{~N}$ dan larutan Na-Silikat adalah 518,2 menit dan 660 menit 
seperti yang ditunjukkan oleh Gambar 1 dan Gambar 2.

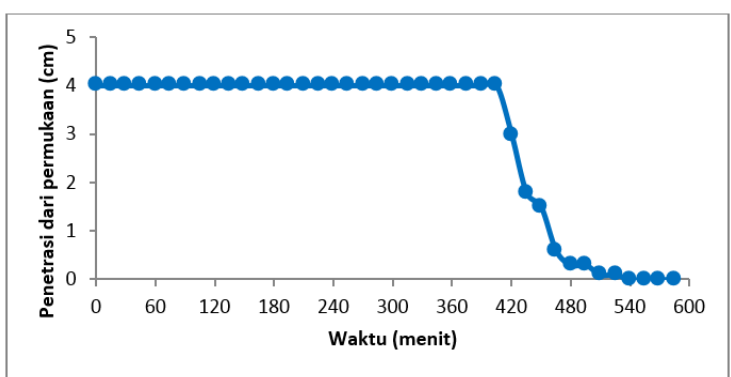

Gambar 1. Hasil uji waktu ikat geopolimer dari metakaolin dan abu bambu dengan aktivator alkali campuran larutan KOH 10 N dan larutan Na-Silikat.

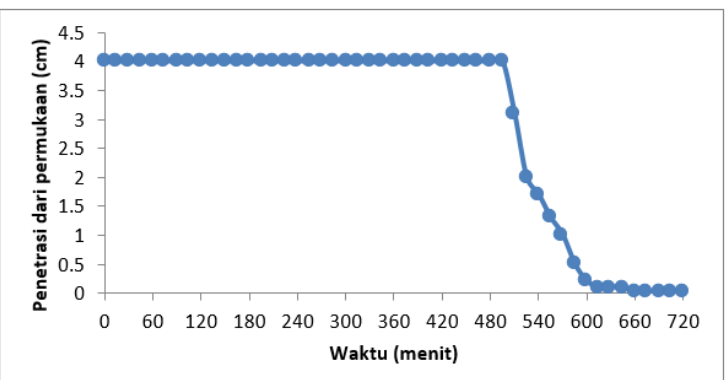

Gambar 2. Hasil uji waktu ikat geopolimer dari metakaolin dan abu bambu dengan aktivator alkali campuran larutan $\mathrm{NaOH} 10$ N dan larutan Na-Silikat.

Waktu ikat awal dan akhir geopolimer dengan aktivator alkali campuran larutan $\mathrm{KOH}$ $10 \mathrm{~N}$ dan larutan Na-Silikat lebih pendek dibandingkan dengan aktivator alkali campuran larutan $\mathrm{NaOH} 10 \mathrm{~N}$ dan larutan $\mathrm{Na}$-Silikat. Hal ini dapat disebabkan oleh ukuran ion $\mathrm{K}^{+}$yang lebih besar dibandingkan ion $\mathrm{Na}^{+}$sehingga geopolimer cenderung lebih cepat menjadi padat (van Jaarsveld dan van Deventer, 1999). Hasil ini tidak berbeda jauh dengan yang diperoleh oleh Palumbo dkk. (2018), yaitu waktu ikat akhir geopolimer dari metakaolin dengan aktivator alkali campuran larutan $\mathrm{NaOH}$ dan Na-Silikat mencapai 9 jam atau 540 menit. Sementara itu waktu ikat awal geopolimer dari metakaolin dengan aktivator alkali larutan $\mathrm{KOH}$ atau larutan $\mathrm{NaOH}$ dapat mencapai lebih dari 1 hari (Mehena dkk., 2017).

\subsection{Analisis SEM}

Gambar 3 dan 4 masing-masing menunjukkan hasil analisis SEM terhadap geopolimer dari metakaolin dan abu bambu dengan aktivator alkali campuran larutan $\mathrm{KOH}$ $10 \mathrm{~N}$ dan larutan Na-Silikat serta campuran larutan $\mathrm{NaOH} 10 \mathrm{~N}$ dan larutan Na-Silikat. Pada kedua geopolimer terlihat adanya fase kontinyu (amorf) yang menunjukkan terbentuknya geopolimer (Davidovits, 2008). Permukaan geopolimer dengan aktivator alkali campuran larutan $\mathrm{KOH} 10 \mathrm{~N}$ dan larutan $\mathrm{Na}-$ Silikat tampak lebih padat dibandingkan permukaan geopolimer dengan aktivator alkali campuran larutan $\mathrm{NaOH} 10 \mathrm{~N}$ dan larutan $\mathrm{Na}-$ Silikat.

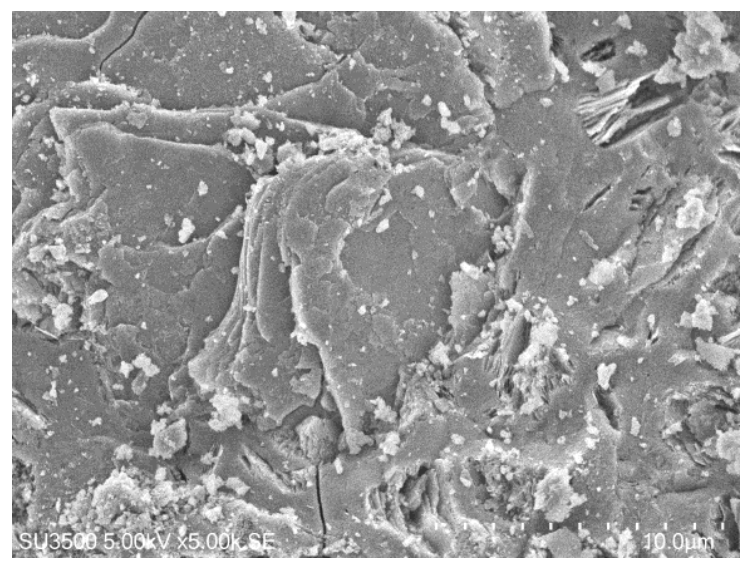

Gambar 3. Hasil analisis SEM geopolimer dari metakaolin dan abu bambu dengan aktivator alkali campuran larutan KOH 10 N dan larutan Na-Silikat.

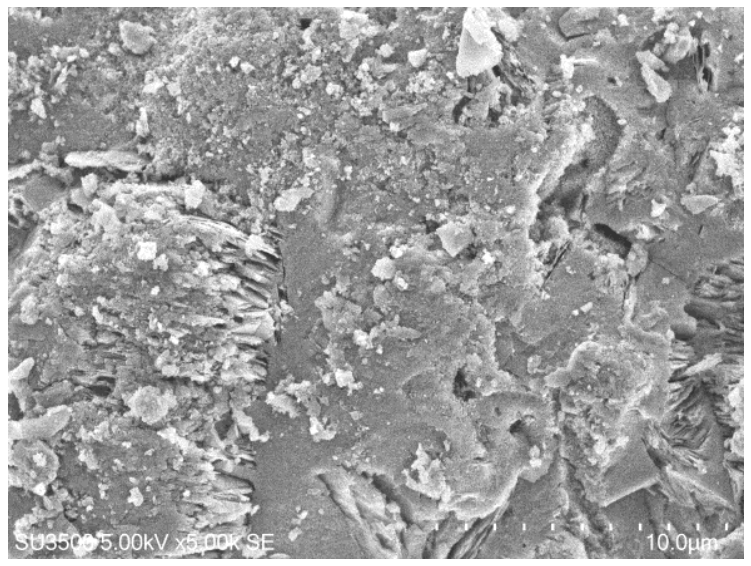

Gambar 4. Hasil analisis SEM geopolimer dari metakaolin dan abu bambu dengan aktivator alkali campuran larutan $\mathrm{NaOH} 10$ N dan larutan Na-Silikat. 


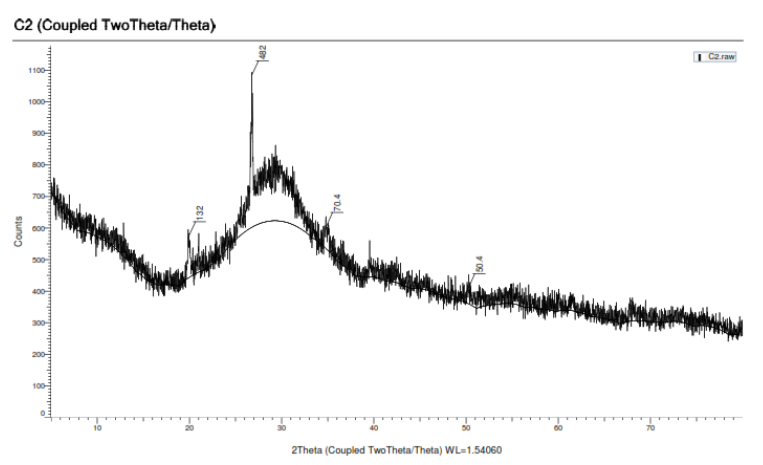

Gambar 5. Hasil analisis XRD geopolimer dari metakaolin dan abu bambu dengan aktivator alkali campuran larutan KOH 10 N dan larutan Na-Silikat.

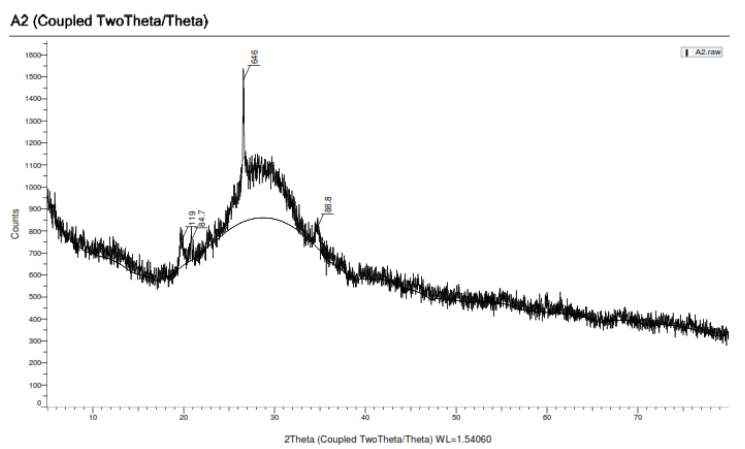

Gambar 6. Hasil analisis XRD geopolimer dari metakaolin dan abu bambu dengan aktivator alkali campuran larutan $\mathrm{NaOH} 10$ N dan larutan Na-Silikat.

\subsection{Analisis XRD}

Hasil analisis XRD terhadap geopolimer dari metakaolin dan abu bambu dengan aktivator alkali campuran larutan $\mathrm{KOH} 10 \mathrm{~N}$ dan larutan Na-Silikat ditunjukkan oleh Gambar 5, sedangkan dengan aktivator alkali campuran larutan $\mathrm{NaOH} 10 \mathrm{~N}$ dan larutan Na-Silikat ditunjukkan oleh Gambar 6. Puncak difraksi yang lebar pada $27-29^{\circ} 2 \theta$ menunjukkan telah terbentuk geopolimer (Davidovits, 2008). Berdasarkan hasil analisis XRD kedua geopolimer mempunyai kandungan struktur amorf yang hampir sama. Kandungan struktur amorf dalam geopolimer dengan aktivator alkali campuran larutan $\mathrm{KOH} 10 \mathrm{~N}$ dan larutan $\mathrm{Na}-$ Silikat sebesar $65,5 \%$ dan kandungan struktur amorf dalam geopolimer dengan aktivator alkali campuran larutan $\mathrm{NaOH} 10 \mathrm{~N}$ dan larutan $\mathrm{Na}-$ Silikat sebesar $66,9 \%$.

Pada kedua geopolimer terlihat adanya kristal. Geopolimer dengan aktivator alkali campuran larutan $\mathrm{KOH} 10 \mathrm{~N}$ dan larutan $\mathrm{Na}-$ Silikat mengandung kristal dari mineral leucite atau $\mathrm{KAlSi}_{2} \mathrm{O}_{6}\left(2 \theta: 19,949^{\circ}\right)$ dan quartz atau
$\mathrm{SiO}_{2}\left(2 \theta: 26,776^{\circ}\right)$. Adapun geopolimer dengan aktivator alkali campuran larutan $\mathrm{NaOH} 10 \mathrm{~N}$ dan larutan Na-Silikat mengandung kristal dari mineral hydrosodalite atau $\mathrm{Na}\left(\mathrm{AlSiO}_{4}\right) \cdot \mathrm{H}_{2} \mathrm{O}$ $\left(2 \theta: 19,753^{\circ}\right)$ dan quartz $\left(2 \theta: 26,606^{\circ}\right)$.

\section{KESIMPULAN}

Geopolimer telah dibuat dari campuran metakaolin dan abu bambu dengan dua macam aktivator alkali, yaitu campuran larutan $\mathrm{KOH} 10 \mathrm{~N}$ dan larutan Na-Silikat serta campuran larutan $\mathrm{NaOH} 10 \mathrm{~N}$ dan larutan Na-Silikat serta dikaji waktu ikat dan mikrostrukturnya. Geopolimer dengan aktivator alkali campuran larutan $\mathrm{KOH} 10$ $\mathrm{N}$ dan larutan Na-Silikat mempunyai waktu ikat awal dan akhir yang lebih pendek serta mengandung mineral leucite dan quartz, sedangkan geopolimer dengan aktivator alkali campuran larutan $\mathrm{NaOH} 10 \mathrm{~N}$ dan larutan Na-Silikat mempunyai waktu ikat awal dan akhir yang lebih panjang serta mengandung mineral hydrosodalite dan quartz. Kedua geopolimer menunjukkan adanya fase kontinyu dan kandungan struktur amorf yang relatif sama.

\section{DAFTAR PUSTAKA}

ASTM C191. 2008. Standard test methods for time of setting of hydraulic cement by Vicat needle. West Conshohocken: ASTM International.

Benhelal, E., Zahedi, G., Shamsaei, E., dan Bahadori, A. 2013. Global strategies and potentials to curb $\mathrm{CO}_{2}$ emissions in cement industry. Journal of Cleaner Production, 51: 142-161.

Davidovits, J. 2008. Geopolymer: Chemistry and applications, 2nd ed. Saint-Quentin: Institut Géopolymère.

Davidovits, J. 2017. Geopolymers: Ceramiclike inorganic polymers. Journal of Ceramic Science and Technology, 8(3): 335-350.

Depperin. 2009. Roadmap industri semen. Jakarta: Direktorat Jenderal Industri Agro dan Kimia, Departemen Perindustrian.

Gartner, E. 2004. Industrially interesting approaches to "low- $\mathrm{CO}_{2}$ " cements. Cement and Concrete Research, 34: 1489-1498. 
Hardjito, D., Cheak, C., C., dan Ing, C.H.L. 2008. Strength and setting times of low calcium fly ash-based geopolymer mortar. Modern Applied Science, 2(4): 311.

Hawa, A., Tonnayopas, D., Prachasaree, W., dan Taneerananon, P. 2013. Investigating the effects of oil palm ash in metakaolin based geopolymer. Ceramics-Silikaty, 57(4): 319-327.

Komnitsas, K. dan Zaharaki, D. 2007. Geopolymerisation: A review and prospects for the minerals industry. Minerals Engineering, 20: 1261-1277.

Mehena, O., Amar, I., dan Raoul, J. 2017. Strength and setting times of metakaolincement-based geopolymer pastes. American Journal of Civil and Environmental Engineering, 2(4): 30-36.

Palumbo, G., Iadicicco, A., Messina, F., Ferone, C., Campopiano, S., Cioffi, R., dan Colangelo, F. 2018. Characterization of early age curing and shrinkage of metakaolin-based inorganic binders with different rheological behavior by Fiber Bragg Grating sensors. Materials, 11(10): 1-14.

Purbasari, A., Samadhi, T.W., and Bindar, Y. 2016. Thermal and ash characterization of Indonesian bamboo and its potential for solid fuel and waste valorization. International Journal of Renewable Energy Development, 5(2): 95-100.

Semen Indonesia, PT. 2015. Laporan Tahunan. Jakarta: PT Semen Indonesia (Persero) Tbk.

Tippayasam, C., Keawpapasson, P., Thavorniti, P., Panyathanmaporn, T., Leonelli, C., dan Chaysuwan, D. 2014. Effect of Thai kaolin on properties of agricultural ash blended geopolymers. Construction and Building Materials, 53: 455 - 459.

van Jaarsveld, J.G.S. dan van Deventer, J.S.J. 1999. Effect of the Alkali Metal Activator on the Properties of Fly AshBased Geopolymers. Industrial and Engineering Chemistry Research, 38, 3932 - 3941. 